\title{
LAS MEDIDAS COERCITIVAS ALEMANAS (EN SENTIDO RESTRINGIDO) COMO EQUIVALENTES A LAS DILIGENCIAS DE INVESTIGACIÓN EN EL PROCEDIMIENTO PENAL
}

\author{
GERMAN COERCIVE MEASURES (IN A RESTRICTED SENSE) \\ AS EQUIVALENT TO INVESTIGATION DILIGENCES IN \\ CRIMINAL PROCEEDINGS
}

SEM SANDOVAL REYES*

\section{Resumen}

Cuando se trata de medidas que en el marco de un procedimiento penal pueden afectar intensamente los derechos fundamentales del imputado o de terceros, la doctrina alemana, en general, no distingue entre diligencias de investigación y medidas cautelares. A diferencia de gran parte de Iberoamérica, todo suele tratarse en el capítulo de las "medidas coercitivas". Esto genera dificultades en el trabajo científico, sobre todo en el ámbito de la comparación. Por eso, este artículo se enfoca en el estudio de las "medidas coercitivas" alemanas, y explica por qué, en un sentido restringido, podría establecerse una equivalencia entre ellas y las "diligencias de investigación". Esta aproximación puede sentar las bases para un tratamiento general, abstracto y sistemático de las diligencias de investigación, las cuales, a pesar de su extraordinaria relevancia práctica, adolecen de un desarrollo científico importante.

\section{Palabras Clave}

Medidas coercitivas - diligencias de investigación - prisión preventivaEingriffs-und Zwangsmaßnahmen - strafprozessuale Zwangsmaßnahmen. 


\begin{abstract}
In the case of measures which, in criminal proceedings, may have an intense impact on the fundamental rights of the accused or third parties, German doctrine generally does not distinguish between investigative measures and precautionary measures. Unlike much of Latin America, everything is usually dealt with in the "coercive measures" chapter. This creates difficulties in scientific work, especially in the field of comparison. Therefore, this article focuses on the study of German "coercive measures", and explains why, in a restricted sense, equivalence could be established between them and "investigative measures". This approach may lay the groundwork for a general, abstract and systematic treatment of research diligence, which, despite its extraordinary practical relevance, suffers from important scientific development.
\end{abstract}

\title{
Keywords
}

Coercive measures - investigation proceedings - preventive prisonEingriffs-und Zwangsmaßnahmen - strafprozessuale Zwangsmaßnahmen.

\section{INTRODUCCIÓN}

Una vez que en observancia del principio de legalidad los órganos de persecución penal deben proceder a la investigación de la verdad y/o la obtención de antecedentes de investigación, tendrán que desarrollar una serie de actividades procesales, las cuales giran en torno a la noción de diligencias o actos de investigación (en adelante, diligencias de investigación). Esta figura procesal penal permite identificar y agrupar

Artículo recibido para su evaluación el 30 de junio de 2020, y aprobado para su publicación el 21 de julio de 2020.

Abogado, Licenciado en Ciencias Jurídicas, Universidad de Valparaíso (Chile), LL.M y doctorando en la Georg-August-Universität Göttingen, Alemania. Email: sem. sandoval@gmail.com. El autor agradece especialmente a la Dra. Sra. Angie Arce Acuña, Presidenta del Instituto de Victimología de Costa Rica; al Prof. Dr. Sr. Claudio Meneses Pacheco, Profesor de Derecho procesal de la Universidad de Valparaíso (Chile); al Sr. Diego González Lillo, abogado y doctorando de la Universidad de Barcelona, y a los Sres. Álvaro Córdova Carreño y Gonzalo Chiang Cáceres, abogados, quienes con sus observaciones críticas permitieron que este trabajo pudiera ser mejorado. En el mismo sentido, se agradecen las observaciones recibidas en el proceso de revisión por pares en la presente revista. El contenido y las opiniones corresponden únicamente al autor, y no representa necesariamente el punto de vista de las personas mencionadas. 
a todas aquellas medidas que tienen por finalidad esencial, la obtención de antecedentes sobre un hecho punible y la posible intervención que en él le cupo a personas determinadas'. En contraste con ellas, los sistemas que optan por trabajar con el respaldo teórico de las medidas cautelares en el procedimiento penal, cuentan con esta otra gama de medidas, que, siguiendo una posición más o menos aceptada por la doctrina, autorizan la privación de la libertad del imputado con la finalidad de asegurar el desarrollo del procedimiento penal, la conservación de las pruebas personales y materiales del juicio y la ejecución de la eventual sentencia ${ }^{2}$.

En un plano normativo, esta concepción de una fase de investigación compuesta grosso modo por diligencias de investigación y medidas cautelares personales, se traduce en una regulación particularizada que, tratándose de las diligencias de investigación, con mayor o menor acierto y precisión, intenta responder preguntas básicas sobre la medida individual de que se trate. Así, por ejemplo, cuáles son las concretas diligencias de investigación que se regulan en la ley, cuáles son los supuestos en que opera, quiénes son los sujetos legitimados para impetrarlas, cuáles son las formalidades y límites para ejecutarlas y cuáles son los mecanismos procesales de control, ya sean judiciales, administrativos, ex ante, o ex

1 Véanse: LÓPEZ MASLE, Julián: "La prueba”. En: Horvitz Lennon, María Inés; López Masle, Julián: Derecho procesal penal chileno. Tomo 2, Santiago, 2005. pp. 68-131; HORVITZ LENNON, María Inés: "Procedimiento ordinario por crimen o simple delito de acción penal pública". En: Horvitz Lennon, María Inés; López Masle, Julián: Derecho procesal penal chileno. Tomo 1, Editorial Jurídica de Chile, Santiago, 2003. pp. 489-494, 507-540; CASTRO JOFRÉ, Javier: Manual de Derecho procesal penal. Editorial Libromar, Santiago, 2017. pp. 218 y ss. y 251 y ss. Referencias sobre esta figura en el Derecho procesal español pueden encontrarse especialmente en las lecciones 7a., 8a. y 10a. de GÓMEZ COLOMER, Juan Luis. En: Montero Aroca, Juan, et. al.: Derecho Jurisdiccional III, Proceso penal. 25a. Ed., Tirant lo Blanch, Valencia, 2017. pp. 171193; 195-238; 239-268; ARMENTA DEU, Teresa: Lecciones de Derecho procesal penal. 10a. Ed., Marcial Pons, Madrid, 2017. pp. 161-218; NIEVA FENOLL, Jordi: Derecho procesal III (Proceso penal). Marcial Pons, Madrid, 2017. pp. 191-234 y 253 y ss.

2 Consúltese el concepto de medidas cautelares personales en el Derecho procesal penal chileno: MATURANA MIQUEL, Cristián; MONTERO LÓPEZ, Raúl: Derecho procesal penal. Tomo 1, 2a. Ed., AbeledoPerrot/Thomson Reuters, Santiago, 2012. p. 478; AGUILAR, ARANELA, Cristián: Medidas cautelares personales y reales en el proceso penal. Editorial Metropolitana, Santiago, 2014. p. 15 s.; LÓPEZ MASLE, Julián: "Las medidas cautelares en el proceso penal”. En: Horvitz Lennon, María Inés; López Masle, Julián: ob. cit.. Págs. 344 s.; DURÁN FUICA, Rodrigo: Medidas cautelares personales en el proceso penal. 2a. Ed., Librotecnia, Santiago, 2007. Págs. 108 s.; CASTRO JOFRÉ, cit., p. 252; MARÍN GONZÁLEZ, Juan Carlos: "Las medidas cautelares personales en el nuevo Código Procesal Penal chileno". En: Revista de Estudios de la Justicia, Nr. 1, Santiago, 2002. p. 9. 
post $^{3}$. En el caso de las medidas cautelares personales, debe destacarse que el Código Procesal Penal chileno (En adelante CPPCh) reconoce expresamente esta noción en el Título V del Libro I, arts. 122 y ss. CPPCh${ }^{4}$. En la misma línea, regula como especies de medidas cautelares personales, la citación (Art. 123 y ss CPPCh), la detención (Art. 125 y ss. CPPCh), la prisión preventiva (Art. 139 y ss. CPPCh) y las medidas cautelares alternativas a la prisión preventiva (Art. $155 \mathrm{ss}$. CPPCh).

Desde un punto de vista teórico y regulativo, la mayoría de los sistemas procesales penales latinoamericanos se estructuran sobre bases similares. Por eso podemos fácilmente investigar, comparar, aprender $\mathrm{y}$ en general, trabajar científicamente con ellos $^{5}$. Tampoco existe mayor dificultad cuando el mismo ejercicio se realiza con España ${ }^{6}$. El problema, sin embargo, es que no sucede lo mismo con Alemania. Si bien la Ordenanza Procesal Penal alemana (en adelante $\mathrm{StPO}^{7}$ ) cuenta con normas concretas semejantes a las latinoamericanas o españolas, cuando se intentan abordar teóricamente los puntos sobre las diligencias

3 A modo de ejemplo, en el caso chileno pueden verse especialmente los arts. 180 a 226 bis CPPCh, referido a las “actuaciones de la investigación” (párrafo 3ro., Título I, Libro II CPPCh).

4 Dicho Título V se denomina explícitamente: "medidas cautelares personales". Esto implica que ellas dejaron de ser una simple teoría surgida en la Italia de la primera mitad del siglo XX al amparo del Derecho procesal civil. Por el contrario, ellas tienen hoy un expreso reconocimiento legal. Las consecuencias teóricas y prácticas de este hito, debido a su novedad, están por verse. En un primer momento consideramos que ni en la explicación universitaria, ni en la aplicación práctica, debería soslayarse esta circunstancia. Figuras particulares como la citación, la detención, la prisión preventiva y las medidas alternativas a la prisión preventiva, deben ser tratadas como especies de un género mayor: las medidas cautelares. Por ello, si una determinada regulación legal -por ejemplo- omite toda referencia al peligro que se trata de evitar, tanto la defensa como el tribunal, por la vinculación de la medida particular al género medidas cautelares, se encuentran en todo el derecho a exigir que, antes de proceder, la fiscalía acredite el presupuesto cautelar periculum in mora, y, en su caso, exigir que se rechace por infundada la petición del órgano persecutor o un querellante.

5 Por todos tráigase a colación el caso de México, que en su Código Nacional de Procedimientos Penales reconoce expresamente la noción de medidas cautelares y da tratamiento a las diligencias de investigación: véase: PÉREZ DAZA, Alfonso: Código Nacional de Procedimientos penales. Teoría y práctica del proceso penal acusatorio. Tirant lo Blanch, Ciudad de México, 2016. pp. 381-431 ("medidas cautelares") y pp. 530 - 569 ("técnicas de investigación").

6 A modo ilustrativo y por todos, véanse las lecciones 8 a. y 9a. sobre medidas de investigación y la lección 10a. sobre medidas cautelares, en el manual de ARMENTA DEU, cit., pp. 161-250.

7 Por su denominación en alemán: Strafprozessordnung. 
de investigación y las medidas cautelares personales, puede apreciarse que el Derecho procesal penal alemán no sigue necesariamente los cánones del horizonte dogmático hispanoparlante. Esto es evidente, por ejemplo, cuando la doctrina alemana prescinde de la noción teórica de medidas cautelares personales. También lo es, cuando se observa que dentro del acápite de "medidas coercitivas" (u otros títulos semejantes) se incluye a todo un extenso catálogo de medidas, que en un sentido amplio, incluyen, no solo a las que llamaríamos diligencias de investigación, sino que también, a la prisión preventiva.

Es por todo lo anterior que surge la interrogante sobre qué se entiende en Alemania por aquellas medidas que en español han sido ampliamente difundidas como "medidas coercitivas", "medidas de coerción o injerencia", o a través de fórmulas semejantes ${ }^{8}$. Junto con lo anterior, y aún a riego de inexactitudes, debe responderse si ellas, en términos funcionales y/o cualitativos, son más asimilables a las medidas cautelares personales, o por el contrario, a las diligencias de investigación. La pregunta anterior, se ha intentado responder profundizando sobre todo en el Derecho procesal penal alemán, poniéndose el énfasis en aquellos autores que haciendo excepción al tratamiento orientado a la praxis ${ }^{9}$, han realizado aportes para un tratamiento teórico general, abstracto y sistemático de este sector del procedimiento penal.

Cuando se nos pregunta con qué objeto tratamos esta figura alemana, tenemos que aclarar en primer lugar, que muy lejos estamos de aceptar

8 Estas nociones se han extendido fuertemente en Latinoamérica, uno de sus antecedentes puede encontrarse en la gran difusión de la obra procesal penal traducida de Roxin (ROXIN, Claus: Derecho Procesal Penal. Editores del Puerto s.r.l., 2000. (Trad. Córdoba, Gabriela E.; Pastor, Daniel R.). pp. 249 y ss., que titula este capítulo en español como "medidas coercitivas e injerencias en los derechos fundamentales". Con la traducción de la obra procesal penal de Volk, que es otra reciente obra de Derecho procesal penal alemán disponible en español (VOLK, Klaus: Curso fundamental de Derecho Procesal Penal. Editorial Hammurabi/Cedpal, Buenos Aires, 2016. (Trad. Nanzer, Alberto, et al.). pp. 107 y ss., la cual titula el capítulo respectivo como "injerencias y medidas de coerción"; la traducción del vocablo alemán al español, en términos prácticos, adquirió carta de ciudadanía.

9 Lamentablemente, ellos no son la mayoría. La literatura que más abunda se enfoca sobre todo en solucionar problemas de la práctica. Es por eso que en los manuales abundan las largas enumeraciones de medidas coercitivas particulares, las descripciones y las propuestas de soluciones concretas (véase en tal sentido la nota $\mathrm{Nr}$. 47). La dimensión abstracta de este fenómeno, lamentablemente, ocupa a un menor número de profesores. Esto ha sido observado por ejemplo por DUTTGE, Gunnar: Der Begriff der Zwangsmaßnahme im Strafprozessrecht. Nomos, Baden-Baden, 1995. p. 43. 
las cosas acríticamente por el simple hecho de que éstas se escriben en alemán u otro idioma extranjero. Luego, nos encontramos en un sector en que los estudiosos hispanohablantes y los alemanes, en general y objetivamente, no nos comprendemos totalmente, lo que supone un perjuicio importante para la investigación científica, sobre todo, al comienzo de un trabajo de comparación. Por otra parte, entendemos que los apuntes del país europeo pueden ayudar a sentar las bases de una teoría general de las diligencias de investigación, que nos permita superar el trabajo meramente intuitivo y la sola lectura y reproducción de los artículos del CPPCh. A partir de ese desarrollo jurídico y cultural, podríamos discutir de mucho mejor manera y con un alcance universal, por ejemplo, en torno a quiénes son los agentes que deben encontrarse legitimados para ordenar y ejecutar este tipo de medidas; cuáles deben ser los supuestos fácticos y normativos para que operen las diligencias, cuáles son los controles adecuados que deben establecerse, qué tipo de derechos fundamentales se deberían afectar, cuáles son las diligencias de investigación que deben operar por defecto en una persecución inicial, cuáles son los grados de sospecha que se deben acreditar para realizar diligencias que afectan gravemente derechos fundamentales, y de qué manera debe garantizarse la proporcionalidad.

Desde otro punto de vista, existen pocos espacios del Derecho procesal penal de tanta y extrema relevancia práctica como el de las diligencias de investigación. Piénsese que todo lo que aquí se discute puede tener impacto, por solo mencionar algunos ejemplos, en los siguientes aspectos fundamentales del procedimiento penal: la primera actuación del procedimiento y la calidad y derechos del imputado (Art. 7, 93, $94 \mathrm{CPPCh}$ ), la autorización judicial previa de actuaciones o diligencias de investigación (Art. 9 CPPCh), la proposición de diligencias durante la investigación por intervinientes distintos del fiscal (Art. 183 CPPCh), la necesidad de la fiscalía de formalizar la investigación para pedir ciertas diligencias (véase el Art. 230 inc. 2 CPPCh y su más que generosa excepción: Art. $236 \mathrm{CPPCh}$ ), la reapertura de la investigación (Art. $257 \mathrm{CPPCh}$ ), y la exclusión de pruebas provenientes de actuaciones o diligencias declaradas nulas u obtenidas con inobservancia de derechos fundamentales, lo que conecta, como se sabe, con la prueba ilícita (Art. 276 inc. 3 CPPCh). 


\section{LAS MEDIDAS COERCITIVAS EN EL DERECHO PROCESAL PENAL ALEMÁN}

\section{La noción.}

Los rótulos "medidas coercitivas" o "medidas de coerción o injerencia" se utilizan para traducir las denominaciones alemanas "Eingriffs- und Zwangsmaßnahmen", "Zwangsmaßnahmen und Grundrechtseingriffe", "Zwangsmittel und strafprozessuale Grundrechtseingriffe" $\mathrm{o}$, entre otras, "strafprozessuale Zwangsmaßnahmen" ${ }^{10}$. Es decir, un conjunto de numerosas medidas procesales penales reconocidas en la ley, que, en un sentido amplio, autorizan una intervención en los derechos fundamentales del imputado y/o de terceros ${ }^{11}$, todo lo anterior, en dirección a obtener la satisfacción de determinados fines, normalmente procesales ${ }^{12}$.

Estas medidas tienen una gran importancia para el procedimiento penal, sobre todo, cuando sirven una importante función de investigación y posibilitan que el procedimiento penal pueda alcanzar sus fines ${ }^{13}$. La obtención de la verdad, según se sostiene por ciertos autores alemanes, es decisiva para conseguir la justicia y la seguridad jurídica ${ }^{14}$. Dicha

10 Véanse los manuales tradicionales alemanes: KINDHÄUSER, Urs/SCHUMANN, Kay: Strafprozessrecht. 5a. Ed., Nomos, Baden-Baden, 2019. p. 85; VOLK, Klaus/ ENGLÄNDER, Armin: Grundkurs StPO. 9a. Ed., C.H. Beck, München, 2018. p. 52 (Eingriffs- und Zwangsmaßnahmen); ROXIN, Claus/SCHÜNEMANN, Bernd: Strafverfahrensrecht. 29a. Ed., C.H. Beck, München, 2017. p. 232; SCHROEDER, Friedrich-Christian/VERREL, Torsten: Strafprozessrecht. 7a. Ed., C.H. Beck, München, 2017. p. 70 (Zwangsmaßnahmen und Grundrechtseingriffe); KÜHNE, Hans-Heiner: Strafprozessrecht. 9a. Ed., C.F. Müller, Heidelberg, 2015. p. 260; BEULKE, Werner/ SWOBODA, Sabine: Strafprozessrecht. 14a. Ed., C.F. Müller, Heidelberg, 2018. p. 164 (Zwangsmittel und strafprozessuale Grundrechtseingriffe).

11 En este sentido: DUTTGE, cit., pp. 43, 204 s.; AMELUNG, Knut: Rechtsschutz gegen strafprozessuale Grundrechtseingriffe. Duncker \& Humblot, Berlin, 1976. p. 14; HENKEL; Heinrich: Strafverfahrensrecht. 2a. Ed., W. Kohlhammer GmbH, Stuttgart, Berlin, Köln, Mainz, 1968. pp. 289 y ss.; WOLTER, Jünger: "Allgemeiner Überblick über Ermittlungsmaßnahmen und Verfahrenssicherung”. En: ALBIN, Eser/KAISER, Günther/WEIGEND, Ewa (Editores): Viertes deutsch-polnisches Kolloquium über Strafrecht und Kriminologie. Max-Planck-Institut für ausländisches und internationales Strafrecht, Nomos, Baden-Baden, 1991. p. 100; KÜHNE, cit., pág. 262; VOLK, Klaus/ ENGLÄNDER, cit., p. 55; ROXIN, Claus/SCHÜNEMANN, cit., p. 233.

12 KÜHNE, cit., p. 261: "las medidas coercitivas sirven a la seguridad de los fines del procedimiento y no tienen carácter penal". En el mismo sentido WOLTER, cit., pp. $91 \mathrm{~s}$.

13 ROXIN, SCHÜNEMANN, cit., p. 232: "Para la realización del proceso penal las intervenciones en la esfera individual son indispensables (...)".

14 En relación con estas finalidades véanse: VOLK, ENGLÄNDER, cit., pp. 4 s.; NEUMANN; Ulfrid: "Materiale und prozedurale Gerechtigkeit im Strafverfahren". 
función de investigación, sin embargo, no sería la única que servirían las medidas coercitivas. Así lo sostiene Schroeder, quien partiendo de la base de un análisis funcional de las medidas coercitivas, termina sosteniendo una concepción amplia de las mismas. En esta perspectiva, éstas cumplirían además una función de aseguramiento de los medios de prueba, de la realización del procedimiento penal y de la ejecución de la sentencia. Este autor destaca además, que las medidas coercitivas pueden cumplir una función de determinación de los presupuestos procesales y de prevención de nuevos hechos punibles ${ }^{15}$. Para esta concepción, por tanto, las medidas coercitivas, en un sentido amplio, se caracterizarían por una multifuncionalidad.

Alrededor de su característica común, es decir, la intervención que estas medidas suponen en los derechos fundamentales, se distinguen dos tipos de medidas coercitivas ${ }^{16}$. Por una parte se encuentran las medidas coercitivas tradicionales ("herkömmlich"), las cuales se caracterizan por suponer siempre la aplicación de coerción o fuerza. Por ejemplo, este sería el caso de la medida coercitiva de registro de la vivienda del imputado según el §102 StPO. Por otra parte, existen otras medidas coercitivas cuya ejecución, si bien no implican intrínsecamente la aplicación de coerción o fuerza, igualmente suponen una afectación importante en los derechos fundamentales del afectado. Por ejemplo, este sería el caso de la medida

En: Zeitschrift für die gesamte Strafrechtswissenschaft, 1989. pp. 52-54. En términos similares: ROXIN, SCHÜNEMANN, cit., pp. 2-5. Una perspectiva actual en: MURMANN; Uwe: “Über den Zweck des Strafprozesses”. En: Goltdammer's Archiv für Strafrecht, 2004. p. 74.

15 SCHROEDER, VERREL, cit., pp. 73 s.; SCHROEDER, Friedrich-Christian: "Eine funktionelle Analyse der strafprozessualen Zwangsmittel“. En: Juristenzeitung, 1985. pp. 1028 y ss.; SCHROEDER, Friedrich-Christian: "Die Ermittlung des Aufenthaltsortes des Beschuldigten als Anwendungsvoraussetzung strafprozessualer Zwangsmaßnahmen“. En: Goltdammer's Archiv für Strafrecht, 2005. pp. 74 s. Otros autores que directa o indirectamente se refieren a funciones de las medidas coercitivas: ROXIN, SCHÜNEMANN, cit., p. 232; RANFT, Otfried: Strafprozeßrecht. 3a. Ed., Richard Booberg Verlag, Stuttgart et al. p. 225.

16 En relación con la distinción que se individualiza pueden consultarse: AMELUNG, cit., pp. 14-17; KÜHNE, cit., pp. 261 s.; MURMANN, Uwe. En: HEGHMANNS, Michael/ SCHEFFLER; Uwe (Editores): Handbuch zum Strafverfahren. C.H. Beck, München, 2008. p. 203. En esta materia es también relevante la sentencia del Tribunal Constitucional alemán sobre el denominado "derecho a la autodeterminación informativa": BVerfGE 120. p. 274 (especialmente las pp. 302-340). 
de vigilancia de las telecomunicaciones del imputado o de terceros según el $§ 100 \mathrm{a} \mathrm{StPO}^{17}$.

\section{Presupuestos ${ }^{18}$.}

\section{a) Regulación legal y posible afectación de diversos derechos fundamentales.}

Las medidas coercitivas comprenden un conjunto de medidas particulares que tienen un expreso reconocimiento en la ley. La regulación, en la Ordenanza Procesal Penal alemana, se caracteriza por su falta de sistematicidad. Eso puede observarse en su geografía, la cual contempla estas medidas sobre todo en los $\S \S 72$ ss.; 94 ss.; 112 ss.; 131 ss.; y 158 ss. StPO' ${ }^{19}$. Aun cuando en relación con este catálogo se sostiene que determinadas medidas podrían servir no solo un fin represivo, sino también preventivo -distinción cuya aclaración excedería el objeto de este trabajo ${ }^{20}$-, pueden mencionarse como medidas coercitivas represivas, y por ende, medidas propias de una regulación de Derecho procesal penal, las siguientes: la toma de muestras de sangre ( $\$ 81$ a StPO); la investigación molecular y genética (\$81e StPO); el aseguramiento y la incautación de objetos con fines probatorios ( $\$ 94 \mathrm{StPO}$ ); el registro de la vivienda del imputado ( $\$ 102 \mathrm{StPO})$; la investigación encubierta ( $\$ 110 \mathrm{a}$ inc. $1 \mathrm{StPO})$; la vigilancia de las telecomunicaciones ( $\$ 100$ a StPO); el registro on-line (§100b StPO); la vigilancia acústica de la vivienda (§100c StPO); la prisión preventiva ( $\$ 112$ ss. StPO), etc.

17 En relación con la praxis chilena y el art. $134 \mathrm{CPPCh}$, es importante observar que no por el hecho que se encuentre normalizado como "coerción débil" (sic), puede desconocerse que el registro de vestimentas, equipaje y/o vehículo de la persona sorprendida en flagrancia, aún cuando se trate de hechos punibles que solo podrían dar lugar a citación, si representa una afectación importante en los derechos fundamentales del imputado.

18 Más arriba (en la nota Nr. 9) hemos señalado la dificultad de trabajar con este concepto en términos abstractos. Por eso debe aclararse que éstas características han sido elaboradas fundamentalmente con base en los siguientes textos, en todos los cuales puede observarse un determinado esfuerzo de abstracción: ROXIN, SCHÜNEMANN, cit., pp. 232-239; KÜHNE, cit., pp. 260 y ss.; SCHROEDER, VERREL, cit., pp. 70- 74; SCHROEDER, Friedrich-Christian: "Eine funktionelle Analyse (...) “.pp. 1028 y ss.; HENKEL, cit., pp. 273 s.; MURMANN, cit., pp. 203 y ss.

19 Para más detalles véase: SCHROEDER, VERREL, cit., p. 70.

20 Sobre esta diferencia véanse: ZACZYK, Rainer: "Strafjustiz oder Präventivjustiz?". En: Fahl, Christian/Müller, Eckhart; Satzger, Helmut y Swoboda, Sabine (Editores), Festschrift für Werner Beulke zum 70. Geburtstag. C.F. Müller, Heidelberg, 2015. pp. 69-78; KÜHNE, cit., pp. 245-257; DUTTGE, cit., p. 141. 
Debido al carácter heterogéneo de estas medidas, los derechos fundamentales que pueden verse afectados por ellas, son también, numerosos. Así ha sido identificado en Alemania, por ejemplo, por Roxin/Schünemann ${ }^{21}$ y también Kühne ${ }^{22}$, quienes destacan como posible, la afectación de los siguientes derechos fundamentales: La integridad física (véanse las diligencias de los $\S \S 81 \mathrm{a} ; 81 ; 81$ e StPO); el derecho a la autodeterminación informativa (ídem en relación con $\S \S 161$ inc. 1, 163 inc. 1, 110a inc. 1, 100a, 100g, 100i, 100b StPO); la inviolabilidad del domicilio (ídem $\S \S 100 \mathrm{c}, 102 \mathrm{StPO}$ ); la libertad personal del imputado (ídem $\S 112 \mathrm{ff}$. StPO), la propiedad (ídem $\S 94 \mathrm{StPO}$ ), etc.

\section{b) Legitimación y ordenación de las medidas coercitivas.}

Las medidas coercitivas solo pueden ser ordenadas por determinados operadores de la justicia penal. En concordancia con el principio de reserva judicial esta competencia corresponde en primer lugar al juez ${ }^{23}$. En el sistema alemán, sin embargo, también se reconoce legitimación a los órganos de persecución penal. Nos referimos sobre todo a la fiscalía (como "dueña del procedimiento de investigación" ${ }^{24}$ ) y según el caso, a su personal de investigación (Ermittlungspersonen) ( $\$ 152 \mathrm{GVG}^{25}$ ). Estos últimos contarían con una "competencia de urgencia" ("Eilkompetenz"), la cual los autoriza a dictar medidas de investigación sin control judicial previo en casos de "peligro en la demora' ${ }^{26}$ ". En la StPO estos casos son abundantes. La policía y los particulares, por último, sólo juegan un rol marginal en la distribución de estas competencias.

21 ROXIN, /SCHÜNEMANN,. cit., p. 233.

22 KÜHNE, cit., p. 263.

23 KINDHÄUSER, SCHUMANN, cit., p. 50; ROXIN, SCHÜNEMANN, cit., p. 234; BEULKE, SWOBODA, cit., p. 165.

24 KINDHÄUSER, SCHUMANN, cit., p. 52.

25 Gerichtsverfassungsgesetz (Equivalente a la Ley de Organización de los Tribunales).

26 KINDHÄUSER, SCHUMANN, cit., pp. 50 y 85; AMELUNG; Knut: "Die Entscheidung des BVerfG zur, Gefahr im Verzug“'i.S. des Art. 13 II GG“'. En: Neue Zeitschrift für Strafrecht. Heft. 7/2001. p. 338; ROXIN, SCHÜNEMANN, cit., p. 234; RANFT, cit., p. 234. Sobre "el dominio de la policía en el procedimiento de investigación penal" véase: AMBOS, Kai: "Staatsanwaltschaftliche Kontrolle der Polizei, Verpolizeilichung des Ermittlungsverfahrens und organisierte Kriminalität“. En: Juristische Ausbildung, 2003. pp. 677 s. 
Medidas coercitivas que solo pueden ser ordenadas por el juez son, por ejemplo, las siguientes ${ }^{27}$ : La internación del imputado para la preparación de un informe pericial ( $\$ 81 \mathrm{StPO}$ ) y la prisión preventiva ( $\$ 112$ ss. StPO).

El pequeño número de medidas de reserva exclusiva del juez contrasta con aquellas que si bien puede dictar naturalmente el mismo tribunal, forman parte de una competencia que se comparte con la fiscalía, la cual, en caso de "peligro en la demora", se encuentra legitimada para ordenar autónomamente la respectiva medida. Esta es, la que en términos de competencia, legitimación y práctica, se afirma como regla general ${ }^{28}$. Como muestra, sin embargo, obsérvese que la fiscalía podría ordenar autónomamente las siguientes medidas coercitivas que enumeramos ejemplificativamente en el apartado precedente: Así, en el caso de la inspección corporal del imputado y la toma de muestras de sangre (§81a inc. $2 \mathrm{StPO}$ ); la investigación molecular y genética (\$81e en relación con §81f. StPO); el aseguramiento y la incautación de objetos con fines probatorios ( $\$ 94$ en relación con $\S 98$ StPO), el registro del imputado ( $\S$ 102 en relación con $\S 105$ StPO), la investigación encubierta ( $\$ 110 \mathrm{a}$ inc. 1 StPO); el establecimiento de puestos de control en lugares de acceso público ( $\$ 111$ inc. $2 \mathrm{StPO})$; la vigilancia de las telecomunicaciones $(§ 100 \mathrm{a}$ en relación con $\S 100$ e inc. 1 StPO), etc.

\section{c) La justificación de la intervención en la "cláusula general de investigación" 0 en una autorización legal especial.}

Las medidas coercitivas individuales solo pueden ser ordenadas y/o ejecutadas, si se encuentran cubiertas por una ley que autoriza la intervención (Eingriffsermächtigung). Según el Art. 20 inc. $3 \mathrm{GG}^{29}$ la existencia de esta disposición es indispensable ${ }^{30}$. En este contexto se pueden distinguir medidas coercitivas que se encuentran cubiertas por la denominada "cláusula general de investigación" (Ermittlungsgeneralklausel), y otras que solo pueden ser ordenadas $\mathrm{y} / \mathrm{o}$ ejecutadas porque una ley establece específicamente dicha facultad.

27 Seguimos a ROXIN, SCHÜNEMANN, cit., p. 234.

28 Se sigue a ROXIN, SCHÜNEMANN, cit., p. 234.

29 Grundgesetz (Ley Fundamental alemana).

30 En este sentido véanse: MURMANN, cit., p. 203: "intervenciones procesal penales que afectan derechos fundamentales de los ciudadanos requieren una autorización de intervención legal"; en el mismo sentido: MURMANN; Uwe: Prüfungswissen Strafprozessrecht. 4a. Ed., C.H. Beck, München, 2019. p. 26; RANFT, cit., p. 225. 


\section{i) Medidas coercitivas cubiertas por la cláusula general de investigación.}

Tan pronto exista una sospecha inicial en relación con un hecho punible ${ }^{31}$, la fiscalía y la policía cuentan de inmediato, y sin necesidad de una autorización judicial, con una serie de medidas coercitivas que implican intervenciones en la esfera de derechos del afectado. Todas estas se caracterizan por presuponer intervenciones de baja intensidad. También, por el hecho que se encuentran legalmente cubiertas por la denominada "clausula general de investigación". Es decir, el grupo de normas que imponen a los órganos de persecución penal el deber, pero al mismo tiempo, la facultad de tomar medidas para investigar la posible comisión de un hecho punible, apenas exista la señalada sospecha inicial. En este sentido se citan los $\S \S 160$ inc. 1, 161 inc. 1, 163 inc. 1 StPO. ${ }^{32}$

El tenor de los $\S \S 160$ inc. $1^{\circ}$ y 161 inc. $1^{\circ}$ StPO es especialmente ilustrativo. El $\S 160$ inc. $1^{\circ} \mathrm{StPO}$ señala que tan pronto la fiscalía tome conocimiento de la sospecha de un hecho punible, ya sea por denuncia $u$ otro medio, debe tomar la determinación sobre la posibilidad de investigar los hechos. El $\S 161$ inc. $1^{\circ}$ StPO sostiene que la fiscalía se encuentra facultada para exigir informaciones y para poder realizar investigaciones de todo tipo, ya sea por sí misma o a través de servicios y funcionarios del servicio de policía, siempre que dicha facultad no se encuentre regulada por una regla especial.

En esta lógica, los órganos de persecución penal se encuentran facultados para realizar medidas coercitivas como las siguientes: la solicitud de información a servicios públicos; la realización de observaciones discretas

31 En relación con la sospecha inicial (Anfangsverdacht) véase: MURMANN; Uwe: Prüfungswissen. p. 27; ROXIN, SCHÜNEMANN, cit., pp. 320 s.; PETERS, Sebastian: "§ 152 márgen Nr. 35". En: Kudlich, Hans (Editor), Münchener Kommentar zur Strafprozessordnung. Tomo 1, C.H. Beck, München, 2014 (en adelante MüKOcomentarista); GERKE, Björn: "§ 152 márgen Nr. 12". En: Gercke, Björn, et al., Heidelberg Kommentar Strafprozessordnung. 6a. Ed., C.F. Müller, Heidelberg, 2019 (en adelante HK-StPO/comentarista); SCHMITT, Bertram: "§ 152 márgen Nr. 4". En: Schmitt, Bertram/Köhler, Marcus, Meyer-Goßner/Schmitt, Strafprozessordnung. 61a. Ed., C.H. Beck, München, 2018 (en adelante Meyer-Goßner/comentarista).

32 LÖFFELMANN, Markus/WALTHER, Alexander/REITZENSTEIN, Robert: Das strafprozessuale Ermittlungsverfahren. DeutscherAnwaltVerlag, Bonn, 2007. pp. 61-65; KÜHNE, cit., pp. 263-265; HEFENDEHL, ROLAND: "Die neue Ermittlungsgeneralklausel der $\S \S 161,163$ StPO: Segen oder Fluch". En: Strafverteidiger. Nr. 12/2001. Págs. 700-706; HILGER, HANS: "Zum Strafverfahrensrechtsänderungsgesetz 1999 (StVÄG 1999)- 1. Teil”. En: Neue Zeitschrift für Strafrecht. Año 2000. pp. 561-564; VOLK, ENGLÄNDER, cit., p. 52 (ellos aluden al "principio de la libre configuración del procedimiento penal"). 
y por breve plazo; la utilización de informantes y personas de confianza; la obtención de información en el vecindario; la toma de contacto a través de internet y en forma anónima, etc. ${ }^{33}$

\section{ii) Medidas coercitivas que solo pueden ser ordenadas en la medida que se cumplan los presupuestos de una autorización legal especial.}

Si una medida coercitiva no se encuentra cubierta por la cláusula general de investigación, considerando especialmente la intensidad de la intervención que presupone, solo podrá ser ordenada y ejecutada si la ley concede una autorización especial (spezielle Eingriffsermächtigung). En términos concretos, por tanto, es necesario una regulación particular del legislador ${ }^{34}$. Estas regulaciones especiales cuentan con una serie de patrones comunes cuyo conocimiento es importante para responder las preguntas que plantea el objeto de este trabajo. Las principales características las desarrollaremos brevemente en los apartados siguientes.

Las normas que regulan medidas coercitivas especiales establecen la competencia y legitimación para solicitar y ordenar este tipo de medidas. Esto lo pudimos observar claramente cuando tratamos estos aspectos en el punto II, 2, b) precedente, a los cuales nos remitimos. Sin perjuicio de ello, recordamos las ilustrativas palabras de Kühne, quien sostiene que mientras más invasiva sea la intervención de una medida de fuerza en la esfera de derechos individuales, más altos son los presupuestos referidos a la persona facultada para su ordenación ${ }^{35}$.

Las medidas coercitivas especiales pueden exigir diferentes grados de sospecha. El nivel más bajo consiste en la sospecha inicial(Anfangsverdacht). Esto quiere decir, según una noción tipo, que las medidas coercitivas solo podrían ser ordenadas si, según una experiencia criminalística, aparece

33 En estos términos véanse: VOLK, /ENGLÄNDER, cit., pp. 52 s.; MURMANN, cit., p. 205; MURMANN; Uwe: Prüfungswissen. p. 28 (“(...) la cláusula general de investigación solo autoriza intervenciones relativamente mínimas (...)“; HEFENDEHL, cit., p. 703; LÖFFELMANN, WALTHER, REITZENSTEIN, cit., pp. 63 s.

34 En este sentido consúltense: MURMANN, cit., pp. 206 s. Según este autor, los órganos de persecución penal no tienen autorización para sobrepasar la barrera de la "cláusula general de investigación". Tampoco podrían sobrepasar los límites que fijan las autorizaciones legales especiales. En el mismo sentido, MURMANN; Uwe: Prüfungswissen. pp. 26-28; MüKO-Kölbel, “§ 161 márgen Nr. 8”.

35 KÜHNE, cit., p. 267. También consúltese: ROXIN, SCHÜNEMANN, cit., p. 234; BEULKE, SWOBODA, cit., p. 165; KINDHÄUSER, SCHUMANN, cit., p. 50; VOLK, ENGLÄNDER, cit., p. 53. 
como posible la existencia de un hecho punible ${ }^{36}$. Esto contrasta con otros dos niveles diferentes de sospecha: el grado de sospecha suficiente (hinreichender Tatverdacht) y el grado de sospecha vehemente (dringender Tatverdacht). Estos grados de sospecha son especialmente relevantes cuando se piensa en la proporcionalidad de determinadas medidas coercitivas particulares que tienen como consecuencia intervenciones intensas en los derechos fundamentales de los afectados ${ }^{37}$.

El grado de sospecha suficiente es equivalente a aquél nivel de sospecha que exige el tribunal para ordenar la realización del juicio, una vez que la fiscalía ha decidido presentar su acusación ( $\$ 170$ inc. 1, 203 StPO). El grado de sospecha vehemente, según explica Murmann, corresponde a una "alta probabilidad de que el imputado ha cometido un hecho punible". ${ }^{38} \mathrm{El}$ grado de sospecha vehemente es el nivel de sospecha más alto en contra del imputado, naturalmente, antes de la dictación de la decisión definitiva. En el marco del procedimiento penal la sospecha vehemente es un nivel que autoriza la privación de libertad personal del imputado a través de la prisión preventiva ( $\$ 112$ inc. $1 \mathrm{StPO}$ ) o, en su caso, su internación para la preparación de un informe pericial ( $\$ 81 \mathrm{Abs} .2 \mathrm{StPO}){ }^{39}$

Como tercera particularidad debe destacarse que existen medidas coercitivas especiales que sólo pueden ser ordenadas a propósito de la investigación referida a determinados hechos punibles "de considerable significado". Estas disposiciones pueden ser reconocidas porque normalmente contienen un catálogo de hechos punibles respecto de los

36 Nos remitimos a toda la literatura citada en la nota al pié Nr. 31.

37 KÜHNE, cit., p. 227.

38 En estas explicaciones consultamos a MURMANN, Uwe: Prüfungswissen. p. 27; ROXIN, SCHÜNEMANN, cit., p. 321; SCHROEDER,VERREL, cit., p. 43; KÜHNE, cit., p. 227; LOHNER, Erwin: Der Tatverdacht im Ermittlungsverfahren. Begriff, rechtliche Ausgestaltung, praktische Handhabung und Kontrolle am Beispiel der polizeilichen Verdachtsfeststellung. Peter Lang Europäischer Verlag der Wissenschaften, Frankfurt am Main, 1994. pp. 61-65; LÖFFELMANN, WALTHER, REITZENSTEIN, cit., p. 28; WALTHER, Alexander: "§ 170, márgen Nr. 4". En: Krekeler, Wilhelm/Löffelmann, Markus/ Sommer, Ulrich (Hrsg.), Anwaltkommentar Strafprozessordnung. 2a. Ed., DeutscherAnwaltVerlag, Bonn, 2010 (en adelante: AnwK/comentarista); KRAUß, Matthias: “§ 112 márgen Nr. 9". En: Graf, Jürgen Peter (Hrsg.), Strafprozessordnung. 3a. Ed., C.H. Beck, München, 2018 (en adelante: GrafKO-comentarista); Meyer-Goßner/ Schmitt: "§ 112 márgen Nr. 5".

39 En este sentido también SCHROEDER, VERREL, cit., p. 43; VOLK, ENGLÄNDER, cit., p. 56; BEULKE, SWOBODA, cit., p. 153. 
cuales serían aplicables..$^{40}$ De las medidas coercitivas que precedentemente hemos mencionado pueden destacarse como ejemplos, la investigación encubierta ( $\$ 100 \mathrm{a}$ inc. $1 \mathrm{StPO})$; la vigilancia de las telecomunicaciones ( $\$ 100 \mathrm{a}$ StPO); el registro on-line ( $\$ 100 \mathrm{~b}$ StPO); las escuchas domiciliarias (§100c StPO); las medidas de investigación técnica de los aparatos telefónicos móviles ( $\$ 100$ i StPO); etc.

Existen medidas coercitivas -como cuarta particularidad-, que contienen una denominada cláusula de subsidiaridad. Esto significa que la medida coercitiva solo puede ser ordenada cuando, de preferirse una medida menos invasiva, la consecución de sus fines se vería dificultada o ésta perdería en sí toda perspectiva de éxito ${ }^{41}$. Esta manifestación del principio de proporcionalidad ${ }^{42}$ puede reconocerse en los mismos ejemplos de medidas coercitivas particulares mencionadas en el párrafo precedente y que corresponden a los $\S \S 100 \mathrm{a} ; 100 \mathrm{~b} ; 100 \mathrm{c}$ y $100 \mathrm{i}$ StPO.

\section{III. ¿MEDIDAS COERCITIVAS EN EL PROCEDIMIENTO PENAL COMO MEDIDAS CAUTELARES PERSONALES O COMO DILIGENCIAS DE INVESTIGACIÓN?}

\section{Las medidas coercitivas en sentido amplio y su imposibilidad de asimilación.}

Un primer punto de vista podría consistir en asumir como adecuada la propuesta de Schroeder, e intentar trabajar con base en una concepción amplia de las medidas coercitivas, según la cual, estas medidas tendrían un carácter multifuncional, pudiendo servir, en síntesis, una función de investigación, de aseguramiento y de prevención de nuevos hechos punibles $^{43}$. El problema, es que trabajando a este nivel de abstracción, no podría construirse ningún puente teórico que conecte a América Latina con Alemania. A lo sumo, podríamos pensar que solo la reunión teórica de nuestras diligencias de investigación con las medidas cautelares personales podrían tener la escala suficiente para representar la magnitud de un concepto alemán que se nos presenta tan grande como un caballo de troya.

40 Véanse KÜHNE, cit., p. 273; MURMANN, cit., pp. 211-214; RIEß, Peter: "Die ,Straftat von erheblicher Bedeutung' als Eingriffsvoraussetzung. Versuch einer Inhaltsbestimmung". En: Goltdammer's Archiv für Strafrecht, 2004. pp. 623 y ss.

41 En este sentido: KÜHNE, cit., p. 273; MURMANN, cit., pp. 208-211.

42 Consúltense nuevamente: KÜHNE, cit., pp. 265-267; MURMANN, cit., p. 208.

43 Supra II, 1. Véase la literatura citada en la nota al pié Nr. 15. 
Las medidas coercitivas no podrían asimilarse a las medidas cautelares personales, pues ellas, por principio, solo pueden servir una función de aseguramiento procesal. Si ellas fueran utilizadas en una función y/o con una finalidad investigativa, como la deleznable práctica que insta por la pronta privación de libertad del imputado, dando inicio a una secuencia que continúa con el quebrantamiento de su voluntad, la confesión y el término del caso a través de fórmulas de justicia negociada, no quedaría más remedio que calificar semejante despropósito como una medida cautelar apócrifa, clandestina y por ende, antijurídica. ${ }^{44}$

En sentido inverso, lo propio de las diligencias de investigación consiste en la obtención de antecedentes, con los cuales -entre otros- puedan adoptarse decisiones en el marco del procedimiento de investigación, y en general, en el procedimiento penal; o bien, si la fiscalía o la ley así lo determinan, puedan probarse en el juicio las imputaciones contenidas en la acusación. La necesidad de evitar el peligro de fuga, el de oscurecimiento, o el de comisión de nuevos hechos punibles, forma parte del lenguaje de la prisión preventiva. No es, en cambio, el caso de las diligencias de investigación ${ }^{45}$.

\section{Las medidas coercitivas en sentido restringido como diligencias de investigación en el procedimiento penal.}

\section{a) El enfoque restringido.}

Aunque la postura alemana precedente constituya un vistoso ejercicio en términos de sistematización, según señalamos, no nos parece el nivel adecuado donde encontrar respuestas a la pregunta que se nos plantea, a saber, si éstas tienen un símil mayor con nuestras diligencias de investigación o con las medidas cautelares personales. No nos parece convincente buscar la respuesta en cúspides tan altas, donde aquello que se dice como propio de las funciones de las medidas coercitivas, podría también

44 Véase referido a la prisión preventiva alemana y las causales apócrifas de prisión preventiva: NORDHUES, Elmar: Untersuchungshaft im Spannungsverhältnis von Recht und Praxis. Josef Eul Verlag. Köln, 2013. pp. 56, 61 s.; HERRMANN, David: Untersuchungshaft. ZAP Verlag, Münster 2008. pp. 211 s.; EIDAM, Lutz: "Zur Selbstverständlichkeit von Rechtsbrüchen beim Vollzug von Untersuchungshaft". En: Onlinezeitschrift für Höchstrichterliche Rechtsprechung zum Strafrecht. Ausgabe 5/2008. p. 243.

45 Sobre ambas figuras véase Supra I y consúltese la literatura citada en las notas al pié Nr. 1 y 2 . 
terminar predicándose de otras nociones, generando más problemas que soluciones. Piénsese que también podría decirse que, un procedimiento de investigación criminal, en sí, podría cumplir las funciones de investigación, aseguramiento y prevención de hechos punibles ${ }^{46}$.

Es cierto que todas las medidas coercitivas, en un sentido amplio, suponen una injerencia en los derechos fundamentales. En nuestra opinión, sin embargo, esta constatación debe ser tomada solo como un punto de partida. Un enfoque más estricto, luego, debería orientarse a comprender y establecer patrones comunes entre las diferentes y casi inabarcables figuras particulares de este sector de la justicia penal. Este debería ser precisamente el trabajo de la ciencia procesal, tratar de comprender la forma en que opera esta riquísima región. No, en cambio, hacerla invisible. Éste, para nosotros, no sólo es el enfoque correcto, sino que también, el que podría contribuir a resolver el problema sobre la comprensión y asimilación de las medidas coercitivas alemanas en el medio iberoamericano.

\section{b) La equivalencia con las diligencias de investigación.}

Si se presta atención a los indicios que se han venido dando, y aceptamos que, en un sentido restringido, las medidas coercitivas se orientan por la función de obtención de antecedentes o medios de prueba, nos daríamos cuenta que ella, como figura procesal, sería capaz de captar y de representar a la gran mayoría de las medidas particulares en que se piensa cuando en Alemania se trabaja con el rótulo de medidas coercitivas ${ }^{47}$.

46 De hecho el propio Schroeder deduce que, a partir del análisis funcional de las medidas coercitivas, el procedimiento penal, tendría como función la investigación, el aseguramiento de la prueba, el establecimiento de los presupuestos procesales, el aseguramiento de la realización del procedimiento, el aseguramiento de la ejecución y la prevención de hechos punibles. Así en: SCHROEDER, "Eine funktionelle Analyse (...) “, cit, pp. $1032 \mathrm{~s}$.

47 En clave de obtención de antecedentes y/o medios de prueba quedan perfectamente captadas, entre otras, las siguientes medidas particulares: la observación permanente ( $\$ 163 \mathrm{f} \mathrm{StPO}$ ); el examen corporal del imputado y toma de muestras de sangre ( $\$ 81 \mathrm{a}$ StPO); análisis de ADN ( $\S 81$ e-f StPO); la toma de fotografías y de huellas digitales ( $\$ 81 \mathrm{~b}$ StPO); el examen corporal de terceros ( $\$ 81 \mathrm{c}$ StPO); la custodia y la incautación o secuestro ( $\$ 94 \mathrm{StPO}$ ); diversas medidas relacionadas con la vigilancia de las telecomunicaciones $(\S \S 100 \mathrm{a} ; 100 \mathrm{~g} ; 100 \mathrm{i} ; 100 \mathrm{j} ; 100 \mathrm{~b} \mathrm{StPO})$; registro de la persona del imputado o su vivienda ( $\$ 102 \mathrm{StPO})$; las medidas para determinación de la identidad de un sospechoso ( $\$ 163 \mathrm{~b}$ StPO); la utilización de medios técnicos de observación fuera de la vivienda ( $\$ 100 \mathrm{~h}$ StPO); la vigilancia acústica fuera de la vivienda ( $§ 100 \mathrm{f} ; 100 \mathrm{c}$ $\mathrm{StPO})$; la utilización de agentes encubiertos (\$110a StPO), etc. Véase este mismo listado 
En la misma dirección, nos daríamos cuenta que aquello que se menciona como funciones de aseguramiento y de prevención de hechos punibles, en rigor, y sin perjuicio de medidas residuales, puede reconducirse a las funciones propias de una sola medida particular: la prisión preventiva, que en Alemania, en nuestra opinión, constituye el equivalente funcional de las medidas cautelares personales.

Conforme a esta propuesta teórica, la noción amplísima de medidas coercitivas podría ser perfectamente dividida en dos regiones: las medidas coercitivas en sentido restringido y la prisión preventiva alemana. Esto es lo que sucede, en cierta medida, en los manuales de Beulke/Swoboda ${ }^{48} \mathrm{y}$ Kindhäuser/Schumann ${ }^{49}$, cuando, sin daño para la ciencia jurídica alemana, han tratado ambos tipos de medidas en capítulos diferentes ${ }^{50}$.

En esta misma dirección se manifiestan las características que hemos señalado precedentemente. Recuérdese que las medidas coercitivas se encuentran estrechamente vinculadas con la sospecha inicial sobre un determinado hecho punible que la fiscalía y la policía tienen el deber de investigar. Será este el minuto en que entrará en consideración la pregunta, sobre si una medida particular de persecución penal tiene cobertura y justificación en la cláusula general de investigación ( $\$ 160$ inc. $1^{\circ}, 161$ inc. $1^{\circ} \mathrm{StPO}$ ) o, en su caso, en una disposición legal especial (medidas de investigación particulares).

Es, en relación con el problema de elegir la medida investigativa más adecuada, en que los diferentes grados de sospecha y las cláusulas de subsidiaridad que pudieran estar comprometidas, pueden tener la última palabra. Por otra parte, la decisión de conceder legitimación a las propias fiscalías para que, en caso de peligro en la demora puedan ordenar medidas investigativas ${ }^{51}$, está en directa relación con las dinámicas prácticas de una investigación criminal, cuestión que de paso explica, por qué pueden verse afectados diversos derechos fundamentales de un imputado y/o de terceros.

y su desarrollo en extenso en: BEULKE, SWOBODA, cit., pp. 165 y ss. En el mismo sentido: VOLK, ENGLÄNDER, cit., pp. 121 ss.; KINDHÄUSER, SCHUMANN, cit., pp. 85 y ss.

48 BEULKE, SWOBODA, cit., pp. 152 y ss.

49 KINDHÄUSER, SCHUMANN, cit., pp. 130 y ss.

50 Esto no implica que los autores mencionados estén de acuerdo con las ideas que se exponen en este trabajo. La división que realizan en sus textos podrían obedecer a otro tipo de razones, las cuales no se expresan.

51 Cuestión que el autor de este artículo en principio no comparte. 
La prisión preventiva alemana, en términos cualitativos, solo ocupa un espacio particular y concreto dentro de las medidas coercitivas en un sentido amplio. Tal como lo harían las medidas cautelares. Debido a que la prisión preventiva no puede servir una función de investigación ni tampoco ser coadyuvante de investigaciones criminales, no puede sostenerse que ella parta de la base de una "cláusula general de investigación". Tampoco puede establecerse un vínculo directo con el deber de investigar de la fiscalía y la policía.

Por el contrario, el fundamento de la prisión preventiva transita por los caminos de la necesidad de asegurar la realización del juicio y, legislativamente, -contra la fuerte y justificada crítica de la doctrina- por la aspiración de obtener fines preventivos. Por lo tanto, si bien la prisión preventiva supone formalmente la privación del derecho fundamental de la libertad personal, no puede desconocerse que se trata de una medida que es distinta a las medidas coercitivas en un sentido restringido.

Finalmente, valga considerar también, que la prisión preventiva alemana, en concurso con los tipos de detenciones y las medidas alternativas a la prisión preventiva, podría formar su propio sistema autónomo y ubicarse en su centro. Todo lo anterior, a través de sus propios presupuestos, sus propias cláusulas de subsidiaridad internas, y su propia legitimación y procedimiento para ser solicitada y ordenada judicialmente.

\section{CONCLUSIONES}

Las preguntas formuladas al inicio del artículo pueden ser respondidas del modo siguiente:

1. Las medidas coercitivas en el procedimiento penal alemán, en un sentido amplio, pueden entenderse como un conjunto de medidas procesales penales reconocidas en la ley, que autorizan la intervención en los derechos fundamentales del imputado $\mathrm{y} / \mathrm{o}$ de terceros, con miras a obtener la satisfacción de fines procesales consistentes en el eficaz desarrollo de la investigación y el aseguramiento procesal. Con fuerte y justificada crítica de la doctrina, pero a partir de la realidad legislativa, tendría que mencionarse también la orientación a satisfacer fines preventivos.

2. En otra acepción, y aún a riesgo de imprecisiones, la noción amplia de medidas coercitivas podría ser teóricamente dividida en medidas coercitivas en un sentido restringido y en prisión preventiva. Las medidas coercitivas en sentido restringido pueden ser asimiladas a las diligencias 
de investigación, esto es, figuras procesales penales que se orientan a la obtención de antecedentes o medios de prueba referidos a un hecho punible.

3. Las funciones de aseguramiento y de prevención de hechos punibles, en rigor, y sin perjuicio de figuras particulares residuales, pueden reconducirse a las funciones propias de una sola medida particular: la prisión preventiva, que en Alemania, constituye el equivalente de las medidas cautelares personales.

\section{BIBLIOGRAFÍA.}

AGUILAR, ARANELA, Cristián: Medidas cautelares personales y reales en el proceso penal. Editorial Metropolitana, Santiago, 2014.

AMBOS, Kai: "Staatsanwaltschaftliche Kontrolle der Polizei, Verpolizeilichung des Ermittlungsverfahrens und organisierte Kriminalität”. En: Juristische Ausbildung, 2003.

AMELUNG; Knut: "Die Entscheidung des BVerfG zur 'Gefahr im Verzug' i.S. des Art. 13 II GG“. En: Neue Zeitschrift für Strafrecht, Heft. 7/2001.

:Rechtsschutz gegen strafprozessuale Grundrechtseingriffe.

Duncker \& Humblot, Berlin, 1976.

ARMENTA DEU, Teresa: Lecciones de Derecho procesal penal. 10a. Ed., Marcial Pons, Madrid, 2017.

BEULKE, Werner/SWOBODA: Sabine, Strafprozessrecht. 14a. Ed., C.F. Müller, Heidelberg, 2018.

CASTRO JOFRÉ, Javier: Manual de Derecho procesal penal. Editorial Libromar, Santiago, 2017.

DURÁN FUICA, Rodrigo: Medidas cautelares personales en el proceso penal. 2a. Ed., Librotecnia, Santiago, 2007.

DUTTGE, Gunnar: Der Begriff der Zwangsmaßnahme im Strafprozessrecht. Nomos, Baden-Baden, 1995. 
EIDAM, Lutz: "Zur Selbstverständlichkeit von Rechtsbrüchen beim Vollzug von Untersuchungshaft". En: Onlinezeitschrift für Höchstrichterliche Rechtsprechung zum Strafrecht, Ausgabe 5/2008, S.

Disponible en: https://www.hrr-strafrecht.de/hrr/archiv/08-05/hrrs-5-08. pdf

Fecha de última consulta: 11.07.2020

GERCKE, Björn; JULIUS, Karl-Peter; TEMMING, Dieter; ZÖLLER, Mark A. (Editores): Heidelberg Kommentar Strafprozessordnung. 6a. Ed., C.F. Müller, Heidelberg, 2019.

GÓMEZ COLOMER, Juan Luis: "Lección séptima. El procedimiento preliminar: los actos de investigación"; "Lección octava. Los actos de investigación no garantizados" y "Lección décima. Los actos de investigación garantizados (II)". En: Montero Aroca, Juan; Gómez Colomer, Juan Luis; Barona Vilar, Silvia; Esparza Leibar, Iñaki;

Etxeberría Guridi, José F.: Derecho Jurisdiccional III, Proceso penal. 25a. Ed., Tirant lo Blanch, Valencia, 2017.

GRAF, Jürgen Peter (Hrsg.): Strafprozessordnung. 3a. Ed., C.H. Beck, München, 2018.

HEFENDEHL, ROLAND: "Die neue Ermittlungsgeneralklausel der $\S \S 161,163$ StPO: Segen oder Fluch”. En: Strafverteidiger, Nr. 12/2001.

HEGHMANNS, Michael/SCHEFFLER: Uwe (Editores): Handbuch zum Strafverfahren. C.H. Beck, München, 2008.

HENKEL; Heinrich: Strafverfahrensrecht. 2a. Ed., W. Kohlhammer GmbH, Stuttgart, Berlin, Köln, Mainz, 1968.

HERRMANN, David: Untersuchungshaft. ZAP Verlag, Münster 2008.

HILGER, HANS: "Zum Strafverfahrensrechtsänderungsgesetz 1999 (StVÄG 1999)- 1. Teil”. En: Neue Zeitschrift für Strafrecht, año 2000.

HORVITZ LENNON, María Inés: "Procedimiento ordinario por crimen o simple delito de acción penal pública". En: Horvitz Lennon, María Inés; López Masle, Julián, Derecho procesal penal chileno. Tomo I, Editorial Jurídica de Chile, Santiago 2003.

KINDHÄUSER, Urs/ SCHUMANN, Kay: Strafprozessrecht. 5a. Ed., Nomos, Baden-Baden, 2019. 
KUDLICH, Hans (Editor): Münchener Kommentar zur Strafprozessordnung. Tomo 1, C.H. Beck, München, 2014.

KÜHNE, Hans-Heiner: Strafprozessrecht. 9a. Ed., C.F. Müller, Heidelberg, 2015.

KREKELER, Wilhelm/ LÖFFELMANN, Markus/ SOMMER, Ulrich (Hrsg.): Anwaltkommentar Strafprozessordnung. 2a. Ed., DeutscherAnwaltVerlag, Bonn, 2010.

LÖFFELMANN, Markus/ WALTHER, Alexander/ REITZENSTEIN, Robert: Das strafprozessuale Ermittlungsverfahren. DeutscherAnwaltVerlag, Bonn, 2007.

LOHNER, Erwin: Der Tatverdacht im Ermittlungsverfahren. Begriff, rechtliche Ausgestaltung, praktische Handhabung und Kontrolle am Beispiel der polizeilichen Verdachtsfestellung. Peter Lang Europäischer Verlag der Wissenschaften, Frankfurt am Main, 1994.

LÓPEZ MASLE, Julián: “La prueba”. En: Horvitz Lennon, María Inés; López Masle, Julián: Derecho procesal penal chileno. Tomo 2, Santiago, 2005.

: "Las medidas cautelares en el proceso penal". En: Horvitz Lennon, María Inés; López Masle, Julián: Derecho procesal penal chileno. Tomo 1, Santiago, 2003.

MARÍN GONZÁLEZ, Juan Carlos: "Las medidas cautelares personales en el nuevo Código Procesal Penal chileno". En: Revista de Estudios de la Justicia, Nr. 1, Santiago, 2002.

Disponible en: https://rej.uchile.cl/index.php/RECEJ/article/ view/14971/15410

Fecha de última consulta: 14.07.2020.

MATURANA MIQUEL, Cristián: MONTERO LÓPEZ, Raúl: Derecho procesal penal. Tomo 1, 2a. Ed., AbeledoPerrot/ Thomson Reuters, Santiago, 2012.

MURMANN; Uwe: Prüfungswissen Strafprozessrecht. 4a. Ed., C.H. Beck, München, 2019.

: "Über den Zweck des Strafprozesses". En:

Goltdammer's Archiv für Strafrecht, 2004. 
NEUMANN; Ulfrid: "Materiale und prozedurale Gerechtigkeit im Strafverfahren“. En: Zeitschrift für die gesamte Strafrechtswissenschaft, 1989.

NIEVA FENOLL, Jordi: Derecho procesal III (Proceso penal), Marcial Pons, Madrid, 2017.

NORDHUES, Elmar: Untersuchungshaft im Spannungsverhältnis von Recht und Praxis. Josef Eul Verlag, Köln, 2013.

PÉREZ DAZA, Alfonso: Código Nacional de Procedimientos penales. Teoría y práctica del proceso penal acusatorio. Tirant lo Blanch, Ciudad de México, 2016.

RANFT, Otfried: Strafprozeßrecht. 3a. Ed., Richard Booberg Verlag, Stuttgart, München, Hannover, Berlin, Weimar, Dresden, 2005.

RIEß, Peter: "Die 'Straftat von erheblicher Bedeutung" als Eingriffsvoraussetzung. Versuch einer Inhaltsbestimmung". En: Goltdammer's Archiv für Strafrecht, 2004.

ROXIN, Claus/SCHÜNEMANN, Bernd: Strafverfahrensrecht. 29. Ed., C.H. Beck, München, 2017.

ROXIN, Claus: Derecho Procesal Penal. Editores del Puerto s.r.l., 2000. (Trad. Córdoba, Gabriela E.; Pastor, Daniel R.).

SCHROEDER, Friedrich-Christian/VERREL, Torsten:Strafprozessrecht. 7a. Ed., C.H. Beck, München, 2017.

SCHROEDER, Friedrich-Christian: "Die Ermittlung des Aufenthaltsortes des Beschuldigten als Anwendungsvoraussetzung strafprozessualer Zwangsmaßnahmen“. En: Goltdammer's Archiv für Strafrecht, 2005.

:"Eine funktionelle Analyse der strafprozessualen

Zwangsmittel“. En: Juristenzeitung, 1985.

SCHMITT, Bertram/ KÖHLER, Marcus: Meyer-Goßner/Schmitt, Strafprozessordnung. 61a. Ed., C.H. Beck, München, 2018.

WOLTER, Jünger: “Allgemeiner Überblick über Ermittlungsmaßnahmen und Verfahrenssicherung". En: ALBIN, Eser/ KAISER, Günther/ WEIGEND, Ewa (Editores): Viertes deutsch-polnisches Kolloquium über 
Strafrecht und Kriminologie, Max-Planck- Institut für ausländisches und internationales Strafrecht, Nomos, Baden-Baden, 1991.

VOLK, Klaus: Curso fundamental de Derecho Procesal Penal. Traducción de la 7a. Ed. alemana por Nanzer, Alberto; Núñez, Noelia T.; Pastor, Daniel R.; Sarrabayrouse, Eugenio; Editorial Hammurabi/ Cedpal, Buenos Aires, 2016.

VOLK, Klaus/ENGLÄNDER, Armin: Grundkurs StPO. 9a. Ed., C.H. Beck, München, 2018.

ZACZYK, Rainer: "Strafjustiz oder Präventivjustiz?". En: Fahl, Christian/ Müller, Eckhart; Satzger, Helmut y Swoboda, Sabine (Editores): Festschrift für Werner Beulke zum 70. Geburtstag, C.F. Müller, Heidelberg, 2015. 